tions the outcome of a case of vaginal bleeding from the ninth week of pregnancy. With serial samples it may be possible to make this prediction before the ninth week. Thus, in the absence of contraindicating factors, such as maternal age or infertility, low levels would constitute grounds for evacuating the uterus without further delay. That the occasional normal pregnancy might be interrupted is mitigated by the fact that bleeding in early pregnancy carries a high risk of complications in the third trimester. It is also apparent that levels may be low before the onset of bleeding, though the overlap with the normal range would make prediction difficult in the individual subject.

Bleeding in early pregnancy is the commonest cause of emergency admission in young women. The average hospital stay for a patient with an incomplete or inevitable abortion is three days, compared with eight days for a threatened abortion (Department of Health and Social Security, 1968; St. Bartholomew's Hospital Statistics Department, personal communication, 1972). Since the average cost of maintaining a patient in a National Health Service bed exceeds $£ 12$ daily, an investigation costing less that $£ 1$ represents an excellent investment and greatly benefits the patient, who may otherwise have no spend several anxious days separated from her family.

We are indebted to the consultant, nursing, and secretarial staff of the North Middlesex Hospital, London, and to Miss Linda Howard, who performed the assays. The work was supported by grants from the Medical Research Council and the board of governors of St. Bartholomew's Hospital.

\section{References}

Department of Health and Social Security (1968). Report on Hospital Inpatient Enquiry, p. 98. London, H.M.S.O

Genazzani, A. R., Aubert, M. L., Casoli, M., Fioretti, P., and Felber, J.-P. (1969). Lancet, 2, 1385.

Genazzani, A. R., et al. (1971). Fournal of Obstetrics and Gynaecology of the British Commonwealth, 78, 577

Haour, F., Cohen, E., and Bertrand, J. (1971). Revue Européenne d'Études Clinicales et Biologiques, 16, 124.

Letchworth, A. T., Boardman, R., Bristow, C., Landon, J., and Chard, T. (1971). Fournal of Obstetrics and Gynaecology of the British Commonwealth 78,542 .

Saxena, B. N., Emerson, K., and Selenkow, H. A. (1969). New England Fournal of Medicine, 281, 225.

Singer, W., Desiardins, P., and Friesen, H. G. (1970). Obstetrics and Gynecology, 36, 222.

Spona, J., and Janisch, H. (1971). Acta Endocrinologica, 68, 401.

\title{
Renal Failure in Acute Pancreatitis
}

\author{
D. GORDON, R. Y. CALNE
}

British Medical fournal, 1972, 3, 801-802

\section{Summary}

In three patients with acute pancreatitis complicated by renal failure recovery followed dialysis and treatment of associated complications. The records of cases of pancreatitis treated at Addenbrooke's Hospital, Cambridge, suggest that renal failure is a grave and not infrequent complication of acute pancreatitis.

\section{Introduction}

Acute renal failure is known to occur in acute pancreatitis (Howard and Jordan, 1960), but in a recent series (Trapnell, 1971) it was found to be one of the less common of the serious complications of the disease. Our experience is the reverse, that acute oliguria occurs with comparable frequency to the other serious complications of acute pancreatitis-namely, pseudocyst, abscess, and ileus-and must be treated energetically.

Out of 41 new cases of acute pancreatitis admitted under the care of the department of surgery at Addenbrooke's Hospital between July 1966 and April 197214 were associated with biliary tract disease and 7 experienced two or more attacks of pancreatitis. There were six deaths. Six patients $(15 \%)$ developed acute renal failure, all within two weeks of the onset of their illness, and three of these died. "Acute renal failure" has been regarded as present where there was a rise in blood urea to above $100 \mathrm{mg} / 100 \mathrm{ml}$, not relieved by simple fluid replacement, or when there were changes of acute tubular necrosis found at necropsy. Other complications included hypocalcaemia (cor-

Department of Surgery, University of Cambridge, Cambridge R. Y. CALNE, M.S., F.R.C.s., Professor of Surgery

Addenbrooke's Hospital, Cambridge

D. GORDON, M.B., M.R.c.P., Senior House Officer rected serum calcium less than $8.0 \mathrm{mg} / 100 \mathrm{ml}$ ) in 4 cases, pseudocyst or abscess ( 3 cases), and gastrointestinal bleeding ( 1 case).

This report concerns three cases where recovery followed dialysis and treatment of other associated complications.

\section{Case 1}

A 42-year-old American businessman was admitted with a five-day history of severe epigastric pain and vomiting. He was a moderate but not excessive drinker. He had had similar pains before but much less severe. There was pronounced abdominal tenderness. The serum amylase was 188 Somogyi units, and he was treated with antispasmodics and analgesics. Cholecystography and cholangiography were performed, and a barium-meal examination one week after admission suggested a pancreatic cyst. At laparotomy 11 days after admission a pancreatic cyst was drained by a catheter through the right loin.

Two days after operation he became oliguric, and six days after operation intermittent haemodialysis was begun. His general condition continued to decline. He developed atrial flutter and was treated with digoxin. Two weeks after operation he developed a pancreatic fistula through the drain site. On the next day there was massive bleeding through the fistula and per rectum. After transfusion of 20 bottles of blood a laparotomv was performed. The transverse colon had been digested bv th: inflammatory process around the pancreas, and two free ends of howel were completely separated. There was vigorous bleeding from the middle colic artery. The bleeding was controlled, and the colon brought to the abdominal wall as proximal and distal colostomies.

His condition remained extremely poor over the next few weeks, but renal function gradually returned and haemodialvsis was withdrawn. He was discharged after nearly four months in hospital. The continuity of the colon was restored at a later date. He remained well six years after his illness.

\section{Case 2}

A 58-year-old housewife was admitted with severe abdominal pain of three days' duration. On examination there was slight abdominal 
tenderness. The serum amylase was 4,500 Somogyi units and the blood urea was $36 \mathrm{mg} / 100 \mathrm{ml}$. She was treated with intravenous fluids and antibiotics. Three days after admission her urine output began to fall. Her serum calcium fell to $7.6 \mathrm{mg} / 100 \mathrm{ml}$. After 10 days ner blood urea was $346 \mathrm{mg} / 100 \mathrm{ml}$, and intermittent haemodialysis was begun. Laparotomy next day confirmed the diagnosis of pancreatitis. Intermittent haemodialysis was maintained for the next two weeks, when a diuresis occurred. She then made a rapid recovery and was discharged from hospital seven weeks after admission. She was readmitted four months later with a mild attack of pancreatitis, and eight months after her first illness she was readmitted for a second time when a laparotomy and cholecystectomy were performed. The gall bladder contained multiple faceted stones. She remained well one year later.

\section{Case 3}

A 60-year-old training officer was admitted with central abdominal pain and vomiting. There was abdominal tenderness and guarding. The serum amylase was 7,100 Somogyi units and the blood urea was $45 \mathrm{mg} / 100 \mathrm{ml}$. He was treated with analgesics, antispasmodics, antibiotics, and intravenous fluids. He remained well until two days after admission, when he became confused. His blood urea was $101 \mathrm{mg} / 100 \mathrm{ml}$, amylase 4,500 Somogyi units, and serum calcium $5.3 \mathrm{mg} / 100 \mathrm{ml}$. He was treated with additional intravenous calcium. Four days after admission he was very ill and confused, with bilateral pleural effusions, a soft silent abdomen, and a strongly positive Grey-Turner's sign in both flanks. The blood urea was $193 \mathrm{mg} / 100 \mathrm{ml}$, calcium $6.0 \mathrm{mg} / 100 \mathrm{ml}$, amylase 1,300 Somogyi units, and the white cell count was persistently high. Peritoneal dialysis was begun and continued for the next 10 days. He was also treated with intravenous glucagon (Knight et al., 1971). Despite dialysis his blood urea rose to $365 \mathrm{mg} / 100 \mathrm{ml}$ on the next day, and he was comatose and unrousable. He was passing altered blood per rectum and fresh blood was aspirated from the nasogastric tube. He was treated with blood transfusion. The blood sugar rose to $800 \mathrm{mg} / 100 \mathrm{ml}$ and small doses of insulin were given. $\mathrm{He}$ developed an Escherichia coli bronchopneumonia, and was given ampicillin, kanamycin, and oxygen.

He remained in this grave condition for the next three days and then began to show slow improvement. Two weeks later he managed to take a little food. One month after admission he developed a swinging pyrexia, and an abdominal mass was felt. Barium-meal examination showed a swelling $12 \mathrm{~cm}$ in diameter in the head of the pancreas. At laparotomy the mass was found to be a pseudocyst which was drained into the stomach. After the operation he made a slow but steady recovery. He was discharged after more than two months in hospital. He remained well nine months later.

\section{Discussion}

The aetiology of acute renal failure in acute pancreatitis is uncertain. It is often held to be due to a fall in blood pressure and in circulating blood volume due to loss of fluid into the retroperitoneum. In dogs up to $30 \%$ of the blood volume may be lost into the retroperitoneum in an experimental acute pancreatitis (Keith and Watman, 1954). Careful scrutiny of notes and blood pressure charts, however, has failed to show any appreciable changes in blood pressure preceding most of the cases of acute renal failure that we have seen. Possibly toxic products of pancreatic autodigestion are responsible for renal damage. Vasoactive substances are found in the pancreas (Hollenberg et al., 1962) and these might disturb the regulatory mechanisms of the renal circulation.

The present cases show that vigorous treatment of acute renal failure is needed when it occurs in acute pancreatitis. Haemodialysis (Cases 1 and 2) is more efficient and comfortable for the patient but there are risks of disequilibration in such patients with severe electrolyte imbalance, and heparin must be used very cautiously in patients with acute intra-abdominal inflammation. Peritoneal dialysis has the advantage of relative safety, and the action of peritoneal lavage may be beneficial to the pancreatic inflammatory process. Peritoneal dialysis has been advocated as a treatment for uncomplicated acute pancreatitis (Wall, 1965; Bolooki and Gliedman, 1968).

Prevention of acute renal failure in pancreatitis must rely on scrupulous attention to fluid balance and hydration throughout the course of the disease. Further elucidation of the cause of the renal lesion is necessary for more effective prevention.

We would like to thank Mr. W. A. B. Smellie for permission to report Case 2. We would also like to thank Professor M. D. Milne and Mr. Rodney Smith for their help in the care of Case 1, and Dr. D. B. Evans for his help in the care of cases 2 and 3 .

\section{References}

Bolooki, H., and Gliedman, R. L. (1968). Surgery, 64, 466.

Hollenberg, R. M., Kobold, E. E., Pruett, R., and Thal, A. P. (1962). Surgical Forum. Proceedings of the Forum Sessions, Clinical Congress of the American College of Surgeons, 13, 302

Howard, J. M., and Jordan, G. L. (1960). Surgical Diseases of the Pancreas. Philadelphia, Lippincott.

Keith, L. M., and Watman, R. N. (1954). Surgical Forum, Proceedings of the Forum Sessions, Clinical Congress of the American College of Surgeons, 5, 380

Knight, E. J., Condon, J. R., and Smith, R. (1971). British Medical fournal,

2, 440.
Trapnell, J. E. (1971). Annals of the Royal College of Surgeons of England, Wall, A. J. (1965). Medical fournal of Australia, 2, 281.

\section{MEDICAL MEMORANDA}

\section{Transient Ischaemic Attacks and Stroke due to Extracranial Aneurysm of Internal Carotid Artery}

\section{H. G. BODDIE}

British Medical fournal, 1972, 3, 802-803

Aneurysms of the extracranial segment of the internal carotid artery are rare and usually present to the otorhinolaryngologist or vascular surgeon as masses in the peritonsillar or cervical regions respectively.

North Staffordshire Hospital Centre, Stoke-on-Trent, Staffs

H. G. BODDIE, M.R.C.P., Registrar, Department of Neurology (Present address: Muscular Dystrophy Research Laboratory, Newcastle General Hospital, Newcastle upon Tyne)
The following case is unusual in that not only were transient ischaemic attacks culminating in a stroke the mode of presentation, but they occurred in a young man.

\section{Case Report}

A 24-year-old man was admitted to hospital on 2 September 1970 after the sudden onset of a left hemiparesis. For four months from August 1969 he had experienced several transient ischaemic attacks of weakness and paraesthesiae affecting the left upper limb. These were similar, being sudden in onset, associated with right-sided temporal headaches, and followed by complete recovery within an hour. In December 1969 he was admitted to another hospital for investigation of a left hemiparesis of sudden onset. Examination showed a left visual field defect, left facial weakness, and a left hemiparesis and sensory impairment. Investigations, which were repeated on this admission and are described below, suggested that his symptoms and signs were due to recurrent emboli from the right internal carotid artery. He refused surgery 